\title{
Does Preschool Education in Indonesia Meet the Quality Standards?
}

\author{
Abdulkhaleq AL-Rawafi, ${ }^{1, *}$ \\ ${ }^{1}$ Linguistic Department, Universitas Pendidikan Indonesia, Bandung, Indonesia \\ "Corresponding author. Email: rawafi2013@gmail.com
}

\begin{abstract}
Assessment in early childhood education is essential for it could help teachers to understand children's developmental progress in learning, and enable caregivers to determine how well they perform in their job. This study is designed to observe and assess the preschool education in Subang, Indonesia to determine whether the Indonesian children receive a quality educational environment. There are five kindergartens participated in this study. The study adapts the early childhood education rating scale-revised (ECERS-R) published by Harms, Clifford, and Cryer (1998). The instrument consists of five subscales, namely: space and furnishings, personal care, language reasoning, activities, and interaction. Inside these subscales, there are 37 items with four-point scale in which each has a description of 1 (inadequate), 2 (minimal), 3 (good), and 4 (excellent). The researcher carried out the observation and assessment by using the check list 'Yes' if the dimension meets the determined criteria, and 'No' if the dimension does not meet the criteria. The results show that the preschool educational environment in Subang, Indonesia does not meet the criteria of the ECERS-R, especially the language and reasoning and interaction.

Keywords: Assessment, pre-school education, quality standards, Indonesian education
\end{abstract}

\section{INTRODUCTION}

Preschool education is the spark that lights up children's further education. Theoretical and empirical research identify that preschool education has its own characteristics. First, it is one of the important parts of "the basic education and considered as the foundation stages of school education and lifelong education' (He, 2015, p. 116). Second, it develops various skills and competencies such as "communication skills, cultural awareness, creativity, self-awareness, aesthetics, and different social skills" (Acer, 2015, p. 43). Third, and more importantly, it plays a significant role in ensuring children's school readiness (Polat \& Yavuz, 2016). Preparing children's school readiness is concerned with how well each state serves quality education. Research in this regard has shown that children who receive high-quality preschool education experiences have better cognitive and socioemotional outcomes (Brinkman et al., 2016; Admas, 2019; Krnjaja, 2015). In the industrial revolution 4.0, the quality of early childhood education might be concerning, especially in relation to the appropriate use of information technology.

Empirical studies on the assessment of the quality preschool education point to the importance of research in providing benchmarks for the evaluation its validity and reliability. Admas (2019) assessed the quality of early childhood education in Ethiopia by comparing private and government preschools using the Global Guidelines Assessment (GGA) scales. He concluded that private preschools provide better quality compared to the government ones. However, overall, his study revealed that the preschool education is relatively of low quality in four areas, namely environment and physical space, curriculum content and pedagogy, partnership with families and communities, and services for young children with special needs. The same findings were found in Serbia (Krnjaja, 2015), where the preschool education curriculum does not meet the characteristics of high quality contemporary preschool education.

In the Indonesian context, there are a wide range of research on preschool education that focus on various topics. For example, there are research on the international influence upon the Indonesian preschool education (Yulindrasari \& Djoehaeni, 2019), the internationalization of early childhood education in Indonesia (Adriany, 2018), early formal education teacher competence in the learning of dance art in kindergarten (Wulandari \& Kustiawan, 2018), the impact of Indonesian neo-liberal educational reform on kindergarten teachers' professionalism (Yulindrasari \& Ujianti, 2018), and whether early childhood education policies are in favor of Indonesian women (Newberry \& Marpinjun, 2018). Specifically, Brinkman et al. (2016) examine the relationship between preschool quality and children's early development by using the Early Childhood Environment Rating Scalerevised (ECERS_R) to measure the quality and the Early Development Instrument (EDI). His study concluded that classroom quality has a significance influence on the children's development. To this end, there is limited research that explores the quality of preschool education in both rural and urban areas in Indonesia. In addition, the weakness of the research mentioned earlier lies in the fact 
that they evaluate preschool education based on the Indonesian Standards. For these reasons, this study examines how well private and government preschool educational institutions provide educational environment for preschool children.

\section{METHOD}

\subsection{Context of the Study}

This study was conducted in Subang district, a small town in the east of Bandung city. Three pre-schools were chosen purposively to be observed. The researcher chose this district, because the selected schools are located close to the researcher' residence. The researcher could also visit the schools from time to time, and conduct a close observation of their educational environment.

\subsection{Participants}

The participants in this study are three schools located in Subang, Indonesia. The researcher chose the schools for they are among the best schools providing education and care in the city. Before collecting the data, the researcher asked for permission from the persons in charge of the schools to observe and rate their educational environment. Each of the school has an independent administration and teaching staff. The researcher explained the aim of the study to the principals and teaching staff before conducting the observation. The teachers were eager to know about the results of this research. Therefore, the teachers helped the researcher with answering questions that require clarification and accompanied along the observation.

\subsection{Instrumentation}

The study uses an instrument that consists of different dimensions of quality observable in the classroom, namely: children's physical, socio-emotional, and cognitive development. The study adapted the Early
Childhood Environment Rating Scale - Revised (ECERSR), developed by Harms, Clifford, \& Cryer (1998) and redeveloped by (Brinkman et al., 2016) to fit the Indonesian context, which consists of 43 sub-items under six main items as follows.

1) Space and furnishing: Indoor space, furniture for routine care/ play and learning, furnishing for relaxation and comfort, room arrangement, space for privacy, child related display, gross motor play, gross motor equipment $P$

2) Personal care routines: Greeting/ departing, meals/ snacks, nap/ rest, toileting/ diapering, health practices, safety practices

3) Language-reasoning: Books and pictures, encouraging children to communicate, using language to develop reasoning skills, informal use of language

4) Activities: Fine motor, art, music/movement, blocks, sand/water, dramatic play, nature/science, math/number, use of TV/ Video/ and computer, promoting acceptance of diversity

5) Interactions: Supervision of gross motor activities, general supervision of children, discipline, self-child interactions, interactions among children

6) Program structure: Schedule, free play, group time, provisions for children with disabilities

The ECERS-R was designed to assess the quality of early education learning environment in the classroom and/or day home, especially for groups of children aged $2 \frac{1}{2}$ to 5 years old. The scale took a minimum of 3 hours to record observation and scoring. The observer assigned a descriptive value, on a scale from $1-7$ with a description anchored at odd numbers ( $1=$ inadequate situation, $3=$ minimal, $5=$ good situation, and $7=$ excellent situation). The study used the observation-based method by observing children in authentic situations, and gathering information about skills, knowledge and behavior.

\section{FINDINGS AND DISCUSSION}

This section presents detailed analysis of the results of the assessment of the ECERS-R concerning the six criteria used in this study to evaluate the Early Childhood Environmental Education in Subang, Indonesia.

Table 1 The frequency distribution of the assessment of early childhood environmental education in the three seleted schools

\begin{tabular}{|c|c|c|c|c|c|c|c|c|c|c|c|c|}
\hline \multirow{2}{*}{$\begin{array}{l}\text { Assessment of Early Childhood } \\
\text { Environmental Education }\end{array}$} & \multicolumn{4}{|c|}{ Al-Madanni } & \multicolumn{4}{|c|}{ Al-Syifa } & \multicolumn{4}{|c|}{ Al-Fourqan } \\
\hline & 1 & 2 & 3 & 4 & 1 & 2 & 3 & 4 & 1 & 2 & 3 & 4 \\
\hline \multicolumn{13}{|c|}{ [1] SPACE AND FURNITURE } \\
\hline 1. Indoor space & 0 & 3 & 0 & 1 & 0 & 0 & 2 & 2 & 0 & 1 & 1 & 2 \\
\hline $\begin{array}{l}\text { 2. Furniture for routine care, } \\
\text { play, and learning }\end{array}$ & 0 & 0 & 1 & 5 & 3 & 0 & 0 & 5 & 3 & 1 & 1 & 3 \\
\hline $\begin{array}{l}\text { 3. Furnishing for relaxation and } \\
\text { comfort }\end{array}$ & 0 & 0 & 0 & 0 & 0 & 0 & 1 & 0 & 0 & 1 & 0 & 0 \\
\hline
\end{tabular}




\begin{tabular}{|c|c|c|c|c|c|c|c|c|c|c|c|c|}
\hline 4. Room arragement for play. & 0 & 0 & 1 & 5 & 3 & 0 & 0 & 5 & 3 & 1 & 1 & 3 \\
\hline 5. Space for privacy. & 2 & 0 & 1 & 0 & 2 & 0 & 1 & 0 & 2 & 0 & 1 & 0 \\
\hline 6. Child-related display. & 2 & 0 & 1 & 2 & 1 & 0 & 1 & 3 & 1 & 1 & 2 & 1 \\
\hline 7. Space for gross motor play. & 1 & 2 & 1 & 6 & 0 & 1 & 3 & 6 & 1 & 2 & 1 & 6 \\
\hline 8. Gross motor equipment. & 0 & 1 & 0 & 2 & 0 & 0 & 1 & 2 & 0 & 0 & 1 & 2 \\
\hline \multicolumn{13}{|c|}{ [2] PERSONAL CARE ROUTINES } \\
\hline 9. Greeting and departing. & 2 & 0 & 0 & 2 & 2 & 0 & 0 & 2 & 2 & 0 & 0 & 2 \\
\hline 10. Males and snacks. & 4 & 0 & 0 & 4 & 4 & 0 & 0 & 4 & 4 & 0 & 0 & 4 \\
\hline 11. Nap and rest. & 9 & 0 & 0 & 0 & 9 & 0 & 0 & 0 & 9 & 0 & 0 & 0 \\
\hline 12. Toiliting/diapering. & 0 & 0 & 1 & 5 & 0 & 0 & 0 & 6 & 0 & 1 & 0 & 5 \\
\hline 13. Health practices. & 0 & 0 & 0 & 4 & 0 & 0 & 0 & 4 & 0 & 0 & 0 & 4 \\
\hline 14. Safety practices. & 3 & 1 & 2 & 4 & 2 & 1 & 2 & 5 & 2 & 1 & 3 & 4 \\
\hline \multicolumn{13}{|c|}{ [3] LANGUAGE AND RESONANING } \\
\hline 15. Books and pictures. & 3 & 1 & 0 & 5 & 2 & 0 & 0 & 7 & 3 & 0 & 1 & 5 \\
\hline $\begin{array}{l}\text { 16. Encouraging children to } \\
\text { communivcate. }\end{array}$ & 0 & 0 & 2 & 2 & 0 & 0 & 0 & 4 & 0 & 0 & 1 & 3 \\
\hline $\begin{array}{l}\text { 17. Using language to develop } \\
\text { resonaning skills. }\end{array}$ & 0 & 0 & 1 & 2 & 0 & 0 & 0 & 3 & 0 & 0 & 1 & 2 \\
\hline 18. Informal use of language. & 2 & 0 & 1 & 2 & 0 & 0 & 1 & 4 & 0 & 0 & 1 & 4 \\
\hline \multicolumn{13}{|c|}{ [4] ACTIVITIES } \\
\hline 19. Fine motors. & 0 & 0 & 2 & 6 & 0 & 0 & 0 & 8 & 0 & 0 & 3 & 5 \\
\hline 20. Art. & 1 & 0 & 0 & 8 & 1 & 0 & 0 & 8 & 1 & 0 & 0 & 8 \\
\hline 21. Music/movement. & 2 & 3 & 0 & 1 & 1 & 3 & 0 & 2 & 1 & 3 & 0 & 2 \\
\hline 22. Blocks. & 0 & 0 & 0 & 9 & 0 & 0 & 0 & 9 & 0 & 0 & 1 & 8 \\
\hline 23. Sand/water. & 7 & 0 & 0 & 2 & 5 & 0 & 0 & 4 & 7 & 0 & 0 & 2 \\
\hline 24. Dramatic play. & 5 & 1 & 0 & 0 & 0 & 1 & 1 & 4 & 4 & 1 & 0 & 1 \\
\hline 25. Nature/science. & 2 & 2 & 1 & 3 & 2 & 0 & 2 & 3 & 3 & 0 & 2 & 3 \\
\hline 26. Math/Numbers. & 2 & 2 & 1 & 3 & 0 & 0 & 1 & 7 & 2 & 0 & 2 & 4 \\
\hline $\begin{array}{l}\text { 27. Use of TV, Video, and/or } \\
\text { computers. }\end{array}$ & 2 & 1 & 1 & 3 & 2 & 0 & 1 & 4 & 2 & 1 & 1 & 3 \\
\hline $\begin{array}{l}\text { 28. Promoting acceptance of } \\
\text { diversity. }\end{array}$ & 3 & 1 & 0 & 0 & 3 & 0 & 1 & 0 & 3 & 0 & 1 & 0 \\
\hline \multicolumn{13}{|c|}{ [5] INTERACTION } \\
\hline $\begin{array}{l}\text { 29. Suppervision of gross motor } \\
\text { activities }\end{array}$ & 0 & 0 & 0 & 6 & 0 & 0 & 0 & 6 & 0 & 0 & 0 & 6 \\
\hline $\begin{array}{l}\text { 30. General supervision of } \\
\text { children }\end{array}$ & 0 & 0 & 0 & 5 & 0 & 0 & 0 & 5 & 0 & 0 & 0 & 5 \\
\hline
\end{tabular}




\begin{tabular}{|l|c|c|c|c|c|c|c|c|c|c|c|c|}
\hline 31. Discipline & 0 & 0 & 0 & 8 & 0 & 0 & 0 & 8 & 0 & 0 & 0 & 8 \\
\hline 32. Staff-child interactions & 0 & 1 & 0 & 4 & 0 & 1 & 0 & 4 & 0 & 1 & 0 & 4 \\
\hline 33. Interactions among children & 0 & 0 & 0 & 6 & 0 & 0 & 0 & 6 & 0 & 0 & 0 & 6 \\
\hline
\end{tabular}

[6] PROGRAM STRUCTURE

\begin{tabular}{|c|c|c|c|c|c|c|c|c|c|c|c|c|}
\hline 34. Schedule & 2 & 2 & 2 & 3 & 1 & 2 & 1 & 5 & 2 & 2 & 1 & 4 \\
\hline 35. Free play & 0 & 2 & 0 & 4 & 0 & 1 & 1 & 4 & 0 & 1 & 1 & 4 \\
\hline 36. Group time & 0 & 1 & 0 & 4 & 0 & 0 & 1 & 4 & 0 & 0 & 1 & 4 \\
\hline $\begin{array}{l}\text { 37. Provisions for children with } \\
\text { disabilities. }\end{array}$ & 7 & 0 & 0 & 0 & 0 & 7 & 0 & 0 & 0 & 7 & 0 & 0 \\
\hline Total & 71 & 26 & 22 & 127 & 46 & 19 & 24 & 156 & 58 & 26 & 31 & 131 \\
\hline
\end{tabular}

Table 1 presents the frequency distribution of the 37 subitems under six criteria, namely space and furniture, personal care routines, which contain, and are assessed by using four rating scale, namely $1=$ inadequate, $2=$ minimal, 3 = good, 4 = excellent. Language and reasoning, activities, interaction, and program structure. The 37 subitems include points that are more specific (they are not included in this table due to space limit), which are used to rate the quality of the early childhood education in the selected schools under investigation. The data in table 1 are summarized in Figure 1.

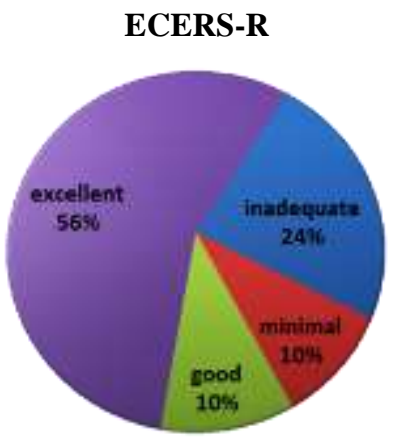

Figure 1 The quality distribution of the ECERS

As Fig.1 shows, the quality of the early childhood education in the three schools is not too good, and at the same time, it is not too bad, reflected with $56.2 \%$ (Excellent). However, improper educational environment is critical, with $23.7 \%$ (Inadequate). Between that appears the good and minimal quality, represented with $10 \%$ each. Those descriptive statistics imply that the early childhood educational environment in Subang, Indonesia does not meet the quality standers used in this assessment. It can be inferred from the total percentage given to the three criteria: inadequate, minimal, and good altogether reaching $44 \%$, compared to $56 \%$ excellent.

In order to gain a clear and detailed sight regarding the quality of the early childhood environment, the six items, namely space and furnishing, personal care routines, language reasoning, activities, interactions, and program structure will be analyzed accordingly.

Previous research found that there are some positive and negative aspects of the use of the ECERS-R in assessing the pre-school environmental education in Indonesia. Among the positives is "observed classroom quality is a significant and meaningful positive predictor of children's development once models correct for measurement error and apply a locally-adapted measure of classroom quality". In contrast, among the negative aspects is "teacher characteristics and structural characteristics are not significant predictors of child development, while holding observed classroom quality constant" (Brinkman et al., 2016). The following sections discuss the findings of the six criteria of the ECERS-R with their sub-criteria based on four evaluation scores, namely excellent, good, minimal, and inadequate, see Fig. 2 below.

\subsection{Space and Furniture}

In this item, there are eight sub-items, namely Indoor space, Furniture for routine care, play, and learning, Furnishing for relaxation and comfort, Room arrangement for play, Space for privacy, Space for gross motor play, Child-related display, and Gross motor equipment. The findings show that there are $23 \%$ inadequate, $27 \%$ minimal, $40 \%$ good, and $17 \%$ excellent, respectively. The result imply that space and future gained good criteria with $40 \%$, which represent highest rate. Lower than that would be the minimal criteria with $27 \%$, followed by $23 \%$ for inadequate criteria. Lower is the criteria excellent with only $17 \%$. Regarding the Space and Furniture, the results found that the schools still lack furniture equipment, such as furniture for relaxation and comfort, cozy area, space for privacy, and quiet area that should be placed far from noisy area. As the idea of the internationalization of preschools emerges in Indonesia, (Adriany, 2018, p. 92-107), most of the Indonesian parents prefer to send their schools to international schools because the parents believe that these schools are a "construction of prestige, considered as privileged in the society, and provide better education for 
better future" (Adriany, 2018, p. 100). Thus, most of the Indonesian pre-schools, in a private sector, are competing to invest much money to ensure that they provide qualified education because the "lack of support from the Indonesian government" (Adriany, 2018, p. 101). In other words, private schools in Indonesia are trying to "translate the global knowledge into the local context" (Adriany, 2018, p. 103). Consequently, the three schools in this study are in their way to transfer this knowledge regarding space and furniture.

The Six Criteria of ECERS-R

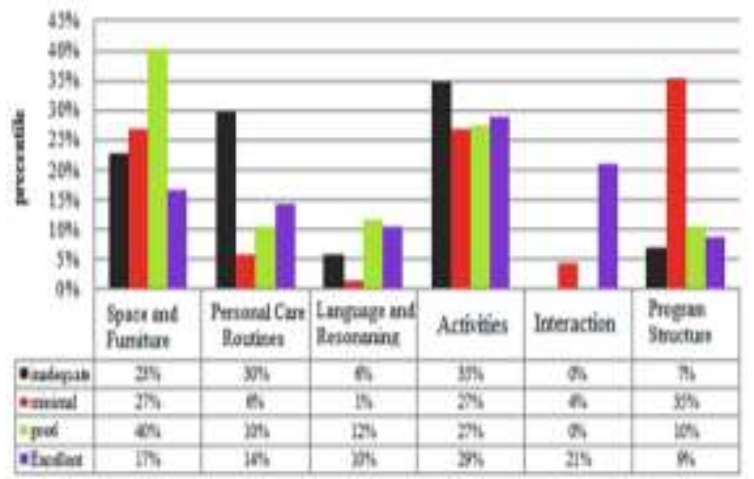

Figure 2 The representation of the six criteria of the ECERS-R

\subsection{Units Personal Care Routines}

The personal care routine is rated inadequate in the three schools. In particular, as it is shown in Fig. 2, inadequate $30 \%$, minimal $6 \%$, good $10 \%$, and $14 \%$ excellent. It is observed that the schools do not provide and serve meals to students. However, the students bring their own food from home, and eat it at the break time. The teachers do not sit and eat with them, they only instruct the children what to say when starting and ending the meal in an Islamic way. The tables and eating surfaces are not sanitized and cleaned appropriately. In addition, the children are not allowed to take a nap and resting due to the short period of the school day, which is four and half hours a day. Thus, the three schools under investigation do not provide any resting room. Toilets are well-cleaned and the children are taught how to use them properly. Although safety must be essential, loose electrical cords and uncovered electric boxes were found, and there was not any product labeling to warn the students from touching them, such as 'keep out of reach of children'. Overall, the results show that many issues concerning personal care routines in the three schools must be given attention for the sake of the children's safety.

\subsection{Language Reasoning}

Language, local or international, is essential in preschool education (Adriany, 2018, p. 100). Language and reasoning in the three schools under investigation gained the least rating with 'fairly well'. The rating ranged from $1 \%$ minimal to $12 \%$ good. In particular, language and reasoning gained $6 \%$ inadequate, $1 \%$ minimal, $12 \%$ good, and $10 \%$ excellent. The staff encouraged the students to communicate and develop reasoning skills. However, they did not use informal language in the class. Books and pictures were rarely used, and were not available throughout the year. In addition, the students did not have books that highlight the diversity of races, cultures, and abilities. The staff of the three schools did not encourage the students to use informal language as it their part of identity.

\subsection{Activities}

Activities items are rated excellent in the rating scale with $35 \%$ points in which Art (e.g., drawing, painting, collage, tools, and other materials) is well used. However, the assessor did not see any materials with 3-dimentional shapes. Based on the researcher's interview and observations with the teachers, they confirmed that they had no idea how the 3-dimentioal shapes work. However, the activities items were rated high. Some weaknesses were in Sand/water, dramatic play, nature/science, use of computers and TVs, and promoting acceptance of diversity.

\subsection{Interaction}

Interaction is rated excellent below the activities rating items. It includes no inadequate and good rating. It gained a minimal with $4 \%$ and excellent with $21 \%$. For example, the staff conducted supervision of gross motor activities and all other activities regularly and effectively. Besides, the staff usually encouraged interaction between staffchildren and children-children. In addition, the staff shoed more discipline in helping the children and problem solving,. In the case of program structure, the programs inside classes were managed and run smoothly.

\subsection{Program Structure}

Program structure is rated minimal. In particular, there are items rated inadequate with $7 \%$, minimal with $35 \%$, good with $10 \%$, and excellent with $9 \%$. However, there was no time set aside the for free play activities and daily outdoor activities. Overall, the program structure gained minimal with $35 \%$ in which the sub-item schedule, free play, group time, and provisions for children with disabilities are not programmed optimally. For example, ample toys, games, and equipment were less provided for free play. It is worth-noting that the provisions for children with disabilities are rated inadequate in this category. The participated schools in this study are not open to children with disabilities. 
Overall, the study used the Early Childhood Environmental rating Scale-Revised (ECERS-R). This assessment shows that the educational environment in the three selected schools in Subang, Indonesia does not meet the characteristics of the ECE quality standards. This is in line with the findings of Krnjaja (2015). However, private preschools provide relatively better quality education compared to government preschools (Admas, 2019; Akhter, 2018). Consequently, ECE in Indonesia should be enhanced, and more funding should be invested to ensure high quality educational programs that adapt the six items and their sub-items of the ECERS-R (Brinkman et al., 2016).

\section{CONCLUSION}

This study concludes that the ECERS-R is recommended measurement assessment tool to measure the quality of the ECE services that can inform educational policy makers to enhance and deliver an adequate early childhood education in Subang, Indonesia. Overall, the ECERS-R assessment of this study shows that the educational environment in the three selected schools does not meet the characteristics of the ECE quality standards. However, previous research claim that "the pre-schools in Indonesia have become a hybrid space where global and local values are interacting and negotiating with one another" (Adriany, 2018). However, the study concludes that there are some items that are rated with excellent such as space and furniture activities, and interaction. Further research is required by using the original ECERS-R to examine the participated schools, which could come up with valid and reliable assessment that can be generalized regarding the preschool environmental education in Indonesia.

\section{ACKNOWLEDGMENT}

This study has been presented in the ECED conference in Jakarta with a recommendation from the Early Childhood Education department at the Universitas Pendidikan Indonesia. The study was supported by the Ministry of Education and Culture, Republic of Indonesia in generously covering the accommodation, meals, and transportation throughout the conference (47 November 2019). The support also covers the publishing. Thank you very much.

\section{REFERENCES}

Acer, D. (2015). The arts in Turkish preschool education. Arts Education Policy Review, 116(1), 4350 .

Admas, F. (2019). Quality of Early Childhood Education in Private and Government Preschools of
Addis Ababa, Ethiopia. International Journal of Early Childhood, 51(2), 163-176.

Adriany, V. (2018). The internationalisation of early childhood education: Case study from selected kindergartens in Bandung, Indonesia. Policy Futures in Education, 16(1), 92-107.

Akhter, N. (2018). Pre-School Education in Bahawalpur: A Situational Analysis of Private and Government Schools. Bulletin of Education and Research, 40(3), 201-217.

Brinkman, S. A., Hasan, A., Jung, H., Kinnell, A., Nakajima, N., \& Pradhan, M. (2016). The role of preschool quality in promoting child development: evidence from rural Indonesia. The World Bank.

Harms, T., Clifford, R. M., \& Cryer, D. (1998). Early childhood environment rating scale. New York: Teachers College Press.

He, Y. (2015). Investigation on the Development of Preschool Education Informationization of Ethnic Region in Gansu, China. International Journal of Higher Education, 4(3), 161-167.

Krnjaja, Ž. (2015). The Quality of Early Childhood Education Curriculum Framework in the Republic of Serbia. Bulgarian Comparative Education Society.

Newberry, J., \& Marpinjun, S. (2018). Payment in heaven: Can early childhood education policies help women too?. Policy Futures in Education, 16(1), 29-42.

Polat, Ö., \& Yavuz, E. A. (2016). The relationship between the duration of preschool education and primary school readiness. Childhood Education, 92(5), 396-404.

Wulandari, R. T., \& Kustiawan, U. (2018). Evaluation Study of Early Formal Education Teacher Competence in Early Childhood Learning Dance at Kindergartens in Malang, Indonesia. Research on Education and Media, 10(1), 3-8

Yulindrasari, H., \& Djoehaeni, H. (2019). Rebo nyunda: Is it decolonising early childhood education in Bandung, Indonesia?. Journal of Pedagogy, 10(1), 5775.

Yulindrasari, H., \& Ujianti, P. R. (2018). Trapped in the reform: Kindergarten teachers' experiences of teacher professionalisation in Buleleng, Indonesia. Policy Futures in Education, 16(1), 66-79. 